\title{
La prejudicialidad en el nuevo Código Procesal Civil Costarricense
}

Luis Mariano Argüello Rojas

Universidad de Costa Rica, Costa Rica

arguellomariano@gmail.com

Fecha de recibido: Enero 2018 / Fecha de aprobación: Mayo 2018

\section{Resumen}

La investigación que aquí se exterioriza intenta desarrollar, desde una perspectiva crítica, los novedosos alcances teóricos y repercusiones prácticas que presenta el instituto procesal de la prejudicialidad dentro del nuevo proceso civil costarricense, ello a partir de la promulgación de la Ley $\mathrm{N}^{\circ} 9342$ publicada el pasado ocho de abril del año dos mil dieciséis, en el Gaceta $N^{\circ} 68$, alcance $N^{\circ} 54$ y que entrará en vigencia el próximo lunes ocho de octubre del año dos mil dieciocho.

\section{Palabras clave}

Proceso Civil / Crisis Procesal / Suspensión del Proceso / Prejudicialidad / Tutela Judicial Efectiva

\section{Abstract}

The research that is outlined here seeks to develop from a critical perspective the novel theoretical and practical repercussions presented by the procedural institute of prejudiciality within the new Costa Rican civil process, as a result of the enactment of Law $N^{\circ} 9342$ published in the past April 8 of the year two thousand and sixteen, in the Gazette No. 68, reach $N^{\circ} 54$ and that will come into force on Monday, October 8, year two thousand and eighteen.

\section{Key words}

Civil Process / Process Crisis / Suspension of the Process / Prejudiciality / Effective Judicial Protection.

\section{Tabla de contenido}

I. Planteamiento inicial; II. La teoría de la crisis procesal; III. Conceptualización; IV. Fundamento normativo; V. Clases de prejudicialidad; VI. La prejudicialidad penal; VII. La prejudicialidad no penal; VIII. Una propuesta de análisis a la luz de dos presupuestos configuradores; IX. Conclusiones; X. Fuentes Consultadas. 


\section{Planteamiento inicial}

El nuevo Código Procesal Civil (Ley $\mathrm{N}^{\circ}$ 9342) proyecta un cambio de $180^{\circ}$ en la forma de plantear, conocer, tramitar y resolver los conflictos jurídicos que se suscitan en las relaciones entre sujetos de derecho privado. La postulación de una filosofía procesal sustentada en un sistema por audiencias, que tiene como sustrato ideológico la potencialización de una serie de principios procesales (v.gr. igualdad procesal, instrumentalidad, buena fe procesal, oralidad, concentración, preclusión, publicidad, etc.), hacen de esta regulación un instrumento de garantías apto para hacer realizable el derecho fundamental de tutela judicial efectiva, al que tienen derecho todas las personas justiciables.

Sin embargo, de este fenómeno de plena metamorfosis procesal deriva la congénita necesidad de la realización de estudios serios que denoten, críticamente, los cambios introducidos y el impacto que tendrán en la dinámica real de los procesos judiciales, de allí la justificación del presente artículo; pues, resulta obligatorio ir desarrollando análisis particularizados de tales cambios y para ello es más que idónea la comprensión exhaustiva de la nueva concepción de la prejudicialidad que presenta el proceso civil costarricense, aspecto al cual se dedica la siguiente reflexión académica.

\section{La teoría de la crisis procesal}

Con no poca frecuencia se olvida lo que antecede a una contienda judicial; por lo general, las personas que acuden a los Tribunales de Justicia lo hacen porque han experimentado un conflicto en sus esferas existenciales, sea a nivel institucional o intersubjetivo, esto les impulsa a buscar una solución a nivel legal, la que suele venir precedida de un método que se denomina proceso.

De esta manera, lo recién indicado resulta vital para emprender bases sólidas de reflexión científica; ya que en ocasiones, los operadores jurídicos esquivan el trasfondo que cimienta su disciplina; el Derecho en general y el proceso jurisdiccional en lo particular no radican, como lo afirma Jhering citado por Enrique Pedro Haba, en el "cielo de los conceptos" (2002, p. 232) sino que, por el contrario, están imbuidos en todo un trasfondo social, que justifica un abordaje más amplio del objeto en estudio.

El proceso jurisdiccional se explica y justifica a partir del conflicto entre los seres humanos, esto es, por decirlo en términos estrictos: "la causa y la razón de ser" como lo afirma Adolfo Alvarado $(2010$, p. I). Precisamente, debido a esa realidad social, los grupos humanos han ensayado a lo largo de la historia diversas maneras de encontrar solución a tales situaciones conflictivas. En este sentido, las respuestas han sido variadas; no obstante, las mismas se podrían circunscribir al paradigma planteado con cierta uniformidad dentro de los cursos de Teoría General del Proceso.

Así, desde alguna perspectiva materialista del Derecho Procesal se entiende que serán la autotutela y autocomposición los mecanismos primigenios de solución de conflictos; en la primera la solución se da por la venganza privada, los juicios de Dios o incluso el duelo, es decir, los mecanismos que tiendan "propia mano" a la resolución del conflicto. Por el contrario, en la segunda, la solución llegará con la ayuda de otros ciudadanos, quienes actúan como amigables componedores, intermediarios, mediadores, entre otros, generando una convergencia para el desenlace de la disputa, esto según Walter Antillón (200I, p. I77)

Establecido muy sumariamente el contenido de los mecanismos de autotutela y autocomposición, es importante indicar que por la insuficiencia de los mismos para solventar la resolución efectiva de los conflictos, la historia de la humanidad, en sus incesantes procesos de dialéctica, tuvo que ensayar la búsqueda de un método diferente, el cual será conocido como heterocomposición, en el que precisamente surge la figura del tercero, colocado supra-partes. 
En esencia, según Gustavo Zagrebelsky es dentro del paradigma heterocompositivo donde se justifica la existencia de un tercero imparcial, impartial e independiente que venga bajo la pretendida objetividad de las leyes -o más bien ductilidad de las mismas (20II, p. I44)- y mediante la implementación del instrumento conocido como: proceso jurisdiccional, a encontrar y consecuentemente sentenciar una solución al conflicto. Sobre esto Gerardo Parajeles, uno de los juristas encargados de redactar la Ley $\mathrm{N}^{\circ} 9342$, establece:

Distinta es la situación del tercero en la heterocomposición, en la que dicha persona, individual o colegiada, a la que la partes previamente han acudido, es el encargado, en virtud de un contrato o por razón de su oficio, de poner fin al conflicto mediante una resolución definitiva. Aquí pues, el tercero se encuentra situado supra-partes, configurando una relación triangular. Dentro de las formas tenemos el arbitraje y el proceso, en las que el árbitro y el juez imponen como consecuencia de su autoridad derivada- bien de una cláusula compromisoria (arbitral) suscrita previamente por las partes, o de la potestad jurisdiccional, la solución definitiva e irrevocable a las partes del litigio. (2005, p. 29)

Así pues, en este ejercicio de concretización se ha hecho notar, por parte de institutos heterocompositivos, la justificación de solución de controversias, sea el arbitraje o el proceso jurisdiccional, pues al fin de cuentas al conflicto como tal, más que eliminarlo se le debe regular tal y como lo afirma Herbert Ortega $(1996$, p. 5) y precisamente tal normativización, desde su perspectiva instrumental, se viene a materializar -entre otros- por la existencia de un proceso civil.

Ahora bien, entrando propiamente al objeto de estudio, puede suceder que en el andar del iter procesal las partes procesales se encuentren con una serie de problemas y entuertos que dificulten la consecución de aquella solución que se pretende alcanzar, mediante la traducción jurídica de su conflicto personal y es que así, como en un viaje por la carretera, los conductores pueden encontrar baches, presas, desviaciones y hasta accidentes, también las partes intervinientes en litigio pueden experimentar situaciones semejantes en su contienda judicial.

Aunado a lo anterior, lo recién señalado es lo que se conoce como "la crisis procesal" término en el que precisamente el sustantivo evoca aquel: "...cambio profundo y de consecuencias importantes en un proceso o una situación o en la manera en que estos son apreciados" (RAE, s.f) de modo que el adjetivo, o sea lo procesal, simplemente viene a circunscribir a un escenario propio el fenómeno antes aludido.

En esta misma línea, esta crisis procesal puede ser de variada índole y naturaleza; sin embargo, para efectos didácticos se podría encasillar dentro de: la interrupción de plazos por caso fortuito o fuerza mayor (Ley 9342, art. 30. I); la actividad procesal defectuosa (lbídem, arts. 31, 32, 33); y la prejudicialidad (lbíd, art 34.2); entre otras.

En coherencia con el planteamiento aquí razonado, Jorge López, uno de los redactores del Código Procesal Civil expresa con sapiencia lo siguiente:

El instituto de la prejudicialidad es uno de los supuestos de lo que la doctrina denomina crisis procesal. La doctrina entiende que existen muchas crisis procesales, la mayoría relacionada con algún tema procesal en particular. Existe crisis procesal cuando se da la suspensión o interrupción del procedimiento y si la prejudicialidad tiene esos efectos, no hay duda que es un supuesto de crisis procesal. (2017, p.185) 
De esta forma y en síntesis, se tiene que, entre otros, existiría crisis procesales en los supuestos de suspensión del proceso como puede acontecer con la prejudicialidad; de modo que, como medida excepcional que irrumpe en la normalidad del proceso, debe ser trazada con nitidez en su concepción para regular su uso pero se debe evitar su abuso y así, consecuentemente, sortear que lo extraordinario se convierta en lo ordinario, como desgraciadamente pasó en buena parte de la vigencia del ahora derogado numeral 202.2 de la vieja ordenanza procesal civil.

Según lo anterior, de allí la importancia de clarificar conceptualizaciones para no caer en juicios apresurados, que por cierto se traducen, en la mayoría de las veces, en consecuencias nefastas para las partes en general y el propio proceso en lo particular.

\section{Conceptualización}

Naturalmente, el proceso civil es un lugar de encuentro de posiciones y no de conceptos; sin embargo, a lo largo de los años la experiencia parece intuir que muchas de aquellas confrontaciones vienen impulsadas por problemas de comprensión de institutos jurídicos que obviamente no son siempre percibidos.

De esta manera, se espera que una persona profesional en Derecho y, más aún, aquella encargada de administrar justicia, conozcan con claridad los contornos, al menos elementales, de ciertos institutos procesales que se erigen como básicos; no obstante, de esperanzas no puede vivir el Derecho Procesal, de allí la importancia de buscar nociones conceptuales, que -si bien no de modo equivoco, pero si al menos aproximativo- brinden bases teóricas para la posterior asimilación pragmática.

En criterio de quien suscribe estas líneas, la prejudicialidad en materia civil opera de oficio o a solicitud de parte cuando, de cara a la resolución del proceso determinado, existe pendiente, ante un mismo Despacho Judicial o un Tribunal distinto, otro proceso judicial no penal en trámite, que no siendo acumulable ni idéntico necesariamente por su objeto principal, sí influye en alguna cuestión o en la decisión final que se pueda tomar en la resolución de aquella contienda judicial, generando como efecto jurídico condicionado la suspensión del curso de las actuaciones de aquel proceso en particular, mientras tanto no se resuelva definitivamente el litigio no penal que genera tal influencia.

En términos gráficos, la anterior definición se podría sintetizar así: en el momento de resolver el litigio civil " $x$ " de oficio o gestión de parte, se tiene noticia de la existencia del proceso no penal " $y$ " que no siendo acumulable ni idéntico, si influye en la contienda " $x$ " de modo que, como efecto jurídico se dispone la suspensión de " $x$ " hasta tanto no se resuelva " $y$ ".

La definición antes indicada es meramente descriptiva más no comprensiva y, como todas, es criticable por omisiones y sesgos teoréticos (omnis definitio in iure civili periculosa est, ut enim non subverti possit), pero busca presentar de buena fe (bona fides) una noción al menos elemental de cómo debe ser entendida la prejudicialidad, sin encasillarse ni tampoco sustraerse de la definición que, como se verá más adelante, brinda el numeral 34.2 de la Ley $\mathrm{N}^{\circ} 9342$.

Asimismo, en adición de luces y para generar un abanico de opciones al paciente lector de estas líneas, importa destacar la definición que sobre el instituto en particular brinda la doctrina procesalista, al respecto De la Oliva citado por el ya mencionado López, conceptualiza:

En sentido estricto y como generalmente se le suele entender, hay prejudicialidad cuando la decisión de la cuestión de fondo principal que constituye el objeto del proceso exige, o tiene como antecedente lógico, resolver previamente otra cuestión sustantiva (no procesal) que en hipótesis podría haber dado lugar -o podría dar lugar en el futuro- a otro proceso en el 
que la cuestión ahora prejudicial sería la cuestión principal. Así, puede hablarse de prejudicialidad civil-civil, penal civil, constitucional-civil etcétera. (2017, p. 185)

Por una parte, como es meridianamente detectable, la cita antes trascrita centra su atención en el razonamiento lógico que debe realizar la persona juzgadora para resolver el conflicto jurídico sometido a estrados, de donde deriva como requisito sine qua non el tener claro el panorama resolutivo de la otra contienda judicial, ese es el antecedente lógico del cual habla el autor en glosa.

Por otra parte, para los autores Sergio Artavia y Carlos Picado la prejudicialidad sería:

...la existencia de otro proceso que impide verter pronunciamiento sobre el civil, al menos válido, hasta tanto no se resuelva el proceso que causa esa prejudicialidad. Prejudicial es todo proceso jurisdiccional pendiente ante un juez diverso a aquel al que le afecta y que deba formarse, con carácter previo, para poder formular la base definitiva sobre la cuestión que se decide el proceso principal. La prejudicialidad guarda una conexión de lógica jurídica con el tema que se debate, de tal manera que la decisión está ligada en relación de subordinación con el objeto principal del proceso. (2016, p. 267)

Unido a lo anterior y con el debido respeto que merecen tan connotados procesalistas, impulsores por cierto de una amplia y rigurosa obra desde la noción teórica denominada garantismo procesal, es de considerar que -en mi humilde criterio- la prejudicialidad no necesariamente se puede presentar ante "un juez diverso a aquel que le afecta", pues nada impide que ante un mismo Despacho Judicial e incluso ante una misma persona juzgadora existan dos procesos judiciales que, no dando lugar ni a litispendencia (Ley 9342, art. 8.6) ni acumulación procesal (Ibídem, art 8.5.), sí generen prejudicialidad; es más el propio numeral 34.2. in fine del Código Procesal Civil (Ley 9342) así lo contempla cuando dispone: “...que a su vez constituya el objeto principal de otro proceso no penal pendiente ante el mismo o distinto tribunal”, de suerte tal que no podría distinguirse cuando la nueva regulación no lo hace, además es de esperar que con las reglas claras de competencia territorial que ostenta la nueva ordenanza procesal (Ibídem, arts. 8.3.I- 8.3.5), esta posibilidad no sea para nada infrecuente.

\section{Fundamento normativo}

Habiendo dejado explícito cuál es el planteamiento de esta reflexión y generando una aproximación conceptual que deriva de la misma comprensión de la teoría de la crisis procesal, es razonable descender a lo prosaico o lo que de ordinario contempla la legislación positiva que informa la materia.

Siguiendo una técnica de redacción bastante depurada, que va de lo general a lo particular, el legislador costarricense ubica a la prejudicialidad dentro del libro primero Normas aplicables a todos los procesos, especialmente a partir de su título segundo Actividad procesal" que se compone -entre otros- de un capítulo primero, Actos procesales y concretamente a partir de la sección sexta Suspensión del procedimiento. En consecuencia, será el artículo 34.2 de la Ley $\mathrm{N}^{\circ} 9342^{8}$ el que recoja como norma general el instituto procesal de la prejudicialidad, que en su tenor literal establece:

\footnotetext{
${ }^{8}$ Para el caso hondureño, la prejudicialidad se encuentra regulada en el artículo 49 del Código Procesal Civil. Por su parte el Código Procesal Civil y Mercantil de El Salvador la regula en su numeral 48. En el caso de la Ley de Enjuiciamiento Civil Española, la establece del numeral 40 al 43.
} 
La existencia de un proceso penal en ningún caso dará lugar a prejudicialidad. Cuando para resolver sobre el objeto del litigio sea necesario decidir acerca de alguna cuestión que a su vez constituya el objeto principal de otro proceso no penal pendiente ante el mismo o distinto tribunal, si no fuera posible la acumulación de procesos, el tribunal, de oficio o a solicitud de parte, podrá decretar la suspensión del curso de las actuaciones. Cuando se haya ordenado instruir proceso penal por falsedad del documento base de una ejecución hipotecaria y prendaria, el remate no se aprobará mientras no haya finalizado el proceso penal. Quedará a opción del oferente mantener o no la propuesta, cuando al efectuarse el remate no se tuviera conocimiento de la existencia del proceso penal.

Como es de notar, la citada disposición permite obtener distintos corolarios, los que en seguida se pasan a exponer:

(i) En primer lugar, la prejudicialidad es una forma de suspensión del proceso, mas no la única; pues también existirá la posibilidad mediante la modalidad del acuerdo de partes por un plazo máximo de dos meses prorrogable (lbídem, art. 34. I) o en los casos establecidos por ley (lbídem, art. 57.I.I).

(ii) La regla de oro y que se erige en un giro copernicano en este ámbito se traduce en que, en ningún caso, el proceso penal suspende al proceso civil, razones de tutela judicial efectiva, experiencia jurisdiccional y posibilidades intraprocesales (V.gr. impugnación por falsedad documental dentro del mismo proceso civil) así lo justifican.

(iii) La prejudicialidad civil lo será únicamente respecto a materia no penal, de esta forma y sin ánimos exhaustivos, podrían hipotizarsen las variantes civilconstitucional, civil-civil, civil-agrario, civil-familia, civil-contenciosoadministrativo, etc.

(iv) La prejudicialidad puede disponerse de oficio o a solicitud de parte; en este último escenario el alegato no equivale a una excepción procesal, sino que se traduce a una mera gestión.

(v) La prejudicialidad se puede dar en relación con un proceso pendiente ante el mismo Despacho o un Tribunal distinto.

(vi) La suspensión decretada en razón de un proceso no penal no está sujeta a un plazo determinado; queda a criterios de lógica, razonabilidad y proporcionalidad el determinar el lapso temporal -distancia temporis- por el cual se decretará la suspensión, situación que debe ser sopesada en ocasión del principio del impulso procesal (lbídem, art 2.5).

(vii) La prejudicialidad es una posibilidad subsidiaria, primero se tiene que descartar la procedencia de una acumulación procesal o en su caso, la existencia de una litispendencia o abuso del proceso.

(viii) Tratándose de ejecuciones hipotecarias y prendarias, el proceso penal sí suspende una fase de aquellos procesos, sea únicamente la aprobación del remate.

(ix) Dispuesta la suspensión de la aprobación del remate por prejudicialidad, queda a opción del oferente mantener o no la propuesta, siempre y cuando no tuviera conocimiento previo de la existencia de aquella causa penal.

(x) Las razones para disponer una prejudicialidad deben ser interpretadas restrictivamente por suponer una limitación a un derecho fundamental, a saber, el derecho a la justicia pronta y cumplida.

(xi) En un sistema por audiencias el momento oportuno para disponer la prejudicialidad podría ser, a guisa de ejemplo, al concluir la audiencia preliminar 
si se está frente a un proceso declarado de puro derecho o bien antes de la convocatoria a audiencia complementaria, en razón de no practicar prueba de forma prematura en afectación del principio de inmediación.

(xii) La resolución que decrete la suspensión del procedimiento es susceptible del recurso de apelación (lbídem, art 67.3.3).

(xiii) Finalmente, si en un proceso penal se declara alguna situación que afecte al civil, cabe la posibilidad de plantear en el proceso civil la excepción de cosa juzgada material (lbídem, art 64) o bien si en el civil ya también existe sentencia, se debe discriminar si se está ante una cosa juzgada material (posibilidad de una demanda de revisión (Ibídem, art 72)) o bien cosa juzgada formal (posibilidad de un incidente de nulidad por las causales de revisión (lbídem, art 33.3)).

Materializada la disección al citado numeral 34.2 del Código Procesal Civil, por un lado, es posible imaginar otras consecuencias o posibles escenarios que funjan -a la fecha- como hipótesis de laboratorio; sin embargo, será la práctica jurisdiccional la que vaya sentando las líneas interpretativas que den contenido a las formas.

Por otro lado, no puede escapar a esta reflexión una regulación especial de la prejudicialidad que opera respecto al proceso sucesorio y que se encuentra emplazada en el numeral 120 del multicitado Código Procesal Civil, el cual establece:

Cuando se presente demanda sobre calidad de sucesores, validez o eficacia del testamento, se suspenderá el proceso sucesorio hasta la resolución definitiva. El mismo efecto tendrán las demandas que afecten la integridad del patrimonio o sobre la existencia, extensión o preferencia de créditos, siempre y cuando el resultado del litigio afecte de tal manera el patrimonio que no sea posible hacer liquidaciones parciales.

Esta regulación ha sido causa de polémicas interesantes, incluso en una de las primeras charlas y/o conferencias introductorias sobre la reforma procesal civil (Poder Judicial, 2016) denominada "Visión y filosofía del Nuevo Código Procesal Civil", realizada el día veintiséis de febrero del año dos mil dieciséis bajo el auspicio de la Escuela Judicial de Costa Rica, se suscitó un encuentro de criterios interesantes entre dos reconocidos civilistas costarricenses.

Así el profesor Álvaro Hernández cuestionó el contenido de la norma, al considerar que la misma desconocía o resultaba contradictoria con la filosofía propuesta por el Código y también con la línea jurisprudencial que a lo largo de los años había propuesto la no suspensión del proceso sucesorio e incluso llamó la atención de estarse ante un eventual "pastoreo" y un "lunar de la reforma", que había generado una oscilación de criterios. Por su parte, para el profesor Parajeles el cuestionamiento resultaba infundado al preceptuar desde su juicio que la prejudicialidad llevaba aparejado, como efecto lógico, que solo se pueda suspender un proceso, pero en el momento final, sea en la etapa de partición o distribución del caudal hereditario.

En realidad, la línea jurisprudencial a la cual hace mención el profesor Hernández, incluso se percibe con claridad en la obra del profesor Parajeles (2010). Así por ejemplo también en Parajeles (2005, p. 74) se indica, entre otros, el Voto del Tribunal Primero Civil, N ${ }^{\circ} 7 \mid 2-M$ de las ocho horas y treinta y cinco minutos del seis de agosto del año mil novecientos noventa $y$ siete, donde se expone el criterio de que un proceso abreviado de unión de hecho no suspende la declaratoria de herederos siendo que si bien "si afectaría la distribución de los bienes, pero a ese momento el A-quo debe tomar las medidas correspondientes para reservar lo que corresponda a esa presunta interesada".

De lo dicho e interpretada la propia letra del antedicho artículo 120 -in claris no fit interpretatioel autor de estas líneas se adhiere a la propuesta del recién mencionado Parajeles; pues véase 
que incluso el numeral en debate contempla una condición particular de tiempo y modo de análisis: "siempre y cuando el resultado del litigio afecte de tal manera que no sea posible hacer liquidaciones parciales" y precisamente para alcanzar esa valoración debe estarse en la etapa final del sucesorio, esto es, en la cuenta partición.

Además, incluso la suspensión no se podría presentar si es factible la distribución parcial, de suerte tal que se coincide como la prejudicialidad especial dispuesta para el sucesorio es congruente con la del artículo 34.2 del Código Procesal Civil, siendo valorable la misma de cara a la resolución final del proceso sucesorio.

De esta manera, queda expuesto el alcance normativo que en adelante ostenta la prejudicialidad civil, razón por la cual se pasará como últimos puntos de esta investigación con el abordaje de las clases o tipologías de prejudicialidad existentes en nuestro medio.

\section{Clases de prejudicialidad}

La nueva ordenanza procesal civil distingue con toda claridad la existencia de dos variantes de prejudicialidad, sea la prejudicialidad penal y la no penal; esta distinción no es en modo alguno arbitraria o caprichosa; sino que es el fruto de la experiencia que durante años evidenció la insuficiencia regulatoria que contenía el derogado artículo 202 inciso 2, del Código Procesal de 1990.

Como un dato interesante, es importante evidenciar que algunas jurisdicciones, a pesar de estar supeditadas por falta de regulación propia a la vía de aplicación supletoria (Código Procesal Contencioso Administrativo, art. 220) prevista en materia procesal civil para el caso de la prejudicialidad, optaron por admitir desde temprano -y siguiendo la línea de algunos Tribunales Civiles- la posibilidad de prejudicialidades en materias ajenas al ámbito penal; de esta manera, del estudio exhaustivo efectuado se cuenta con este valioso antecedente emitido por el Tribunal Procesal Contencioso Administrativo, donde se dispuso la suspensión de un proceso contencioso administrativo frente a un proceso agrario. Al respecto se indicó:

De lo expuesto puede colegirse de forma cristalina que el carácter prejudicial se otorga en relación con el objeto litigioso, que para poder resolverse en forma definitiva el mismo, debe primero decidirse sobre un asunto, que a la vez constituya como el objeto principal de otro proceso que se encuentre pendiente ante el mismo Tribunal u otro distinto, sin que esto deba limitarse únicamente al campo penal. Lo necesario es que exista una relación entre el objeto procesal de ambos asuntos y que uno de ellos deba resolverse primero para que dé cabida al otro o que le permita surgir a la vida jurídica...". (Tribunal Procesal Contencioso Administrativo, Sección Octava, Voto $N^{\circ} 10-2012$ )

En todo caso, las eventuales dudas hermenéuticas quedan disipadas con la claridad teórica que establece la nueva regulación procesal civil, donde como se expresó en líneas pretéritas, es posible la identificación plena de dos clases de prejudicialidad que de seguido se pasan a examinar.

\section{La prejudicialidad penal}

La prejudicialidad penal era la típicamente invocada en los Tribunales de Justicia bajo la vigencia del Código Procesal Civil de 1990 (Ley N ${ }^{\circ}$ 7I30). En efecto la misma se tipificaba en el numeral 202, inciso 2 de aquella ordenación y básicamente disponía:

Cuando, iniciado un proceso penal, la decisión de éste influya necesariamente en la decisión del civil. Esta suspensión no podrá durar más de dos años, al cabo 
de los cuales se reanudará el proceso. No obstante, no se decretará la suspensión si se rindiera garantía suficiente para responder por todo lo que se obtenga de la sentencia y de las costas que se causaren.

Esta regulación generó sendos yerros interpretativos y cuantiosas disfuncionalidades prácticas, puesto que en realidad en la mayoría de los casos no era justificable la suspensión del proceso civil frente al penal; ya que, este último normalmente está asociado con un campo de responsabilidad distinto del civil. A pesar de ello, el tema pasaba injustificablemente desapercibido y muchas veces se suspendían -incluso en la fase inicial o de trámite- procesos civiles o de otras materias con la simple noticia de la existencia de una causa penal abierta, incluso con extremos tan peligrosos como pretender la operatividad de una prejudicialidad sin que siquiera existiera acusación penal formalmente establecida, sino una simple denuncia.

Para colmo de males, la regulación en estudio disponía que esa suspensión "no podía durar más de dos años", sin embargo, esos dos años pasaron a ser prácticamente de aplicación automática con la idea de algunos de atrasar el proceso y desincentivar a la parte contraria al verse quebrado en mil pedazos su derecho a la justicia pronta y cumplida, mientras que para otros significaba la espuria idea de bajar circulantes de sus casillas al pasarlo al estado de "suspendidos".

Con respecto a la excomulgación como regla de la prejudicialidad penal del proceso civil, los ya citados, Artavia y Picado han indicado:

Históricamente consagrada en nuestro Código -en el derogado 202.3 [sic]- la figura de la prejudicialidad penal sobre la civil, se ha entendido, de manera incomprensiva, como aquella que impide verter pronunciamiento en un proceso civil, por estar amarrado o con un obstáculo previo al dictado de la sentencia estimatoria del primer proceso. Ahora el artículo 34.I [sic] ha invertido esa regla histórica, que creó tantos sinsabores, estableciendo como regla "La existencia de un proceso penal en ningún caso dará lugar a prejudicialidad”. Es decir, ya no importa si se aduce la falsedad penal de un documento público o privado, que incida o sea esencial para el dictado de la sentencia de fondo, pues en ningún caso se produce prejudicialidad en este supuesto y en consecuencia no se puede suspender el proceso por ello. (2016, p. 268)

Nuevamente con el debido respeto a la anterior cita, la cual se comparte en su contenido esencial, es menester realizar una aclaración formal muy puntual: en rigor, la prejudicialidad penal estaba contemplada en artículo 202.2 y no en el 202.3 del viejo Código Procesal Civil (CPC), en igual sentido la inversión de aquella odiosa regla se encuentra ahora en ordinal 34.2 y no 34.I del nuevo CPC; sin duda, un mero error material que no afecta la certeza de la sugestiva reflexión aludida.

En suma de argumentos de motivación, la decisión del legislador procesal de excluir la prejudicialidad penal del proceso civil también se considera certera por dos razones:

(i) No existe razón jurídica para que el proceso civil sea servil del proceso penal, en realidad ambas jurisdicciones son independientes y procesalmente no se justifica esa especie de pleitesía que como lastre histórico nubló el proceso civil, pues ambas Sedes pueden operar paralelamente con plena autonomía, como la misma normativa incluso contempla v.gr. proceso de quiebra (Código de Comercio, art. 863 inc. f).

(ii) Asimismo, ahora la falsedad documental sin mayores condicionamientos se puede tramitar en la vía civil y lo que se resuelva se limitará in nuce al proceso en particular; además, de conformidad con el propio numeral 45.5 de la Ley $\mathrm{N}^{\circ} 9342$, lo que se resuelva en la sede penal 
sobre la falsedad de documentos tendrá carácter de cosa juzgada material, de allí la eventualidad -tratándose del proceso ordinario- de la procedencia de esta excepción "privilegiada", ello si el proceso no estuviera concluido (Ibídv.gr.em, art 37.2) o en su caso, el establecimiento de un proceso de revisión en la sede civil ante tal circunstancia (lbídem, art 72).

Establecidas las razones que llevaron a la exclusión de la prejudicialidad penal como regla, salvo la hipótesis ya indicada atrás del tema de la suspensión de la aprobación del remate, se pasará de seguido a visualizar el impacto de la prejudicialidad en otras materias.

\section{La prejudicialidad no penal}

Como se razonó cuando se analizó el fundamento normativo de la prejudicialidad, en la actual regulación la misma básicamente está contemplada para que opere frente a casos no penales.

La idea en su proyección ya había sido recogida en la misma jurisprudencia civil cuando, por ejemplo, el propio Tribunal Segundo Civil de San José, Sección Primera, desde el año dos mil uno en lo que interesa indicaba: "En nuestro medio, el Código Procesal Civil regula únicamente la prejudicialidad con referencia al proceso penal no al civil, sin embargo, esto no quiere decir que las características de éste no se ajusten o no puedan ser aplicadas a lo civil o contencioso...". (Tribunal Segundo Civil de San José, Sección Primera, I55-200I, 200I)

De tal perspectiva, que ya se intuía a nivel pretoriano9, la absoluta razonabilidad de la prejudicialidad respecto de la materia no penal, razones de seguridad jurídica y tutela judicial efectiva así lo imponían. Por su parte, la doctrina nacional también se había mostrado receptora de la idea de la prejudicialidad no penal, así por ejemplo Artavia y Picado (2016, p. 268) mencionan que la introducción de esta figura había sido sugerida por ellos en diferentes momentos de su obra; pues, en su criterio, en el proceso civil pueden darse diversos motivos para decretar la suspensión que en realidad no se encuentran regulados de forma positiva.

En este sentido, se podría plantear una serie de hipótesis en las que es posible la prejudicialidad no penal; por ejemplo, en las variantes civil-constitucional, civil-civil, civil-contencioso administrativo, entre otros.

Asimismo, se podría vislumbrar algunos escenarios interesantes que ejerzan la influencia necesaria para decretar la suspensión procesal del juicio civil, lo anterior claro está, previo al dictado de la sentencia, lo que en razón del sistema por audiencias instaurado en el nuevo proceso civil podría, de no afectar el principio de inmediación (Ley 9342, art. 2.7) decretarse antes de la apertura de la audiencia complementaria si hubiera prueba que practicar (lbídem, art, 102.5) $\circ$ incluso al final de la audiencia preliminar si se tratare de un asunto de puro derecho (lbídem, art 102.4).

A efectos meramente pedagógicos, se esboza el contenido de algunos posibles escenarios. Primeramente, respecto de la prejudicialidad civil-constitucional, no cabe duda de que deberá

\footnotetext{
${ }^{9}$ En igual sentido puede consultarse el Voto $N^{\circ}$ 286-2002 del Tribunal Segundo Civil, Sección Segunda, de las catorce horas treinta y cinco minutos del treinta y uno de julio del dos mil dos, donde en lo medular se resolvió: "En el caso bajo examen se configura un supuesto de prejudicialidad civil en el que no fue posible, como se indicó supra, la acumulación de autos. Cierto que, a diferencia de la legislación procesal civil española, carecemos de una regulación concreta sobre el punto. No obstante, para evitar sentencias contradictorias es factible, por principios generales y por guardar similitud, todo de conformidad con lo dispuesto por los artículos 4 del Código Procesal Civil y 5 párrafos $2^{\circ}$ y $3^{\circ}$ de la Ley Orgánica del Poder Judicial, aplicar el precepto 202 inciso 2 del Código Procesal Civil, matizándolo en el sentido de que la suspensión será hasta que recaiga sentencia firme en el proceso tramitado ante el Juzgado Quinto Civil de Mayor Cuantía de San José, que según constancia de folio 1030 está pendiente de que se resuelva el recurso de casación que se planteó contra el fallo de segunda instancia".
} 
aplicarse, de forma complementaria, la norma general con la especial; esto porque, a nivel de la Ley de la Jurisdicción Constitucional (Ley $\mathrm{N}^{\circ}$ 7I30), la tramitación de una consulta judicial o acción de inconstitucionalidad produce efectos suspensivos dentro del procedimiento administrativo o proceso jurisdiccional en el que se deba aplicar la normativa cuestionada y/o tachada de inconstitucional.

Así, el artículo 82 de la respectiva legislación establece: "En los procesos en trámite no se suspenderá ninguna etapa diferente a la de dictar la resolución final, salvo que la acción de inconstitucionalidad se refiera a normas que deban aplicarse durante la tramitación".

Unido a lo anterior, véase que la norma recién expuesta tiene absolutamente claro que la suspensión lo será únicamente en ocasión del dictado de la resolución final, salvo que se trate de normas atinentes a la tramitación, lo que, por ejemplo, podría acontecer cuando se cuestionen regulaciones de procedimiento propiamente dichas; esta norma con toda naturalidad ha sido aplicada por la misma Sala Constitucional de la Corte Suprema de Justicia, así en el Voto $\mathrm{N}^{\circ}$ 2004-038I I de a las catorce horas con cincuenta y cuatro minutos del veinte de abril del dos mil cuatro, se dispuso:

Para pronunciarse sobre la eventual lesión de los derechos fundamentales del recurrente, es necesario que primero se decida sobre la constitucionalidad del artículo 48 del Reglamento a la ley de Impuestos de Patentes de Actividades Lucrativas de la Municipalidad de San José, en los términos planteados en la Acción de Inconstitucionalidad número 03-0/2/27-007-CO que ha sido interpuesta en este Tribunal. Por lo que, de conformidad con lo dispuesto en los artículos 81 y 82 de la Ley de la Jurisdicción Constitucional, se reserva el dictado de la sentencia de este asunto hasta tanto no sea resuelta la acción de inconstitucionalidad que bajo expediente número 03-012127-0007-CO se tramita ante esta Sala.

Igualmente, en la hipótesis civil-civil se podría presentar aquel caso en el cual si bien los procesos no son acumulables por falta de conexión procesal ${ }^{10} \circ$ ya existe en alguno señalamiento para práctica de prueba, uno de ellos amerita o justifica que sea resuelto de forma prioritaria para dilucidar con claridad el objeto del proceso sujeto a prejudicialidad.

En otras palabras, un expediente donde se alegue por "A" una accesión invertida sobre el inmueble " $D$ " del sujeto "B", pero se tiene noticia de la existencia de otro proceso judicial donde "B" presentó vía reconvención una acción reivindicatoria sobre el terreno " $D$ " en razón de la demanda de usucapión que sobre sobre el mismo planteó el sujeto "C". Como en este segundo proceso se está resolviendo sobre la titularidad del inmueble resulta prudente suspender el juicio de accesión invertida hasta que se dilucide el objeto de aquel otro expediente.

Finalmente, a efectos ejemplificativos, en la fórmula civil-contencioso administrativo, se deberá tener en cuenta que al ser la competencia en esta segunda materia improrrogable (Código Procesal Contencioso Administrativo, art 5), la hipótesis de una acumulación sería prácticamente

\footnotetext{
${ }^{10} \mathrm{Ha}$ sido criterio jurisdiccional que para la acumulación procesal se deben ponderar al menos tres elementos, en primer término, es necesario que se trate de asuntos cuya tramitación y régimen competencial resulten similares. Además y como segundo requisito, las pretensiones no pueden ser excluyentes entre sí, esto es que el conocimiento de una no impida el conocimiento de la otra. Además, debe existir identidad o conexidad procesal; hay identidad de elementos cuando las partes, el objeto y la causa son las mismas. Por su parte, para que se dé la conexión es necesario que sean comunes dos de los elementos o uno solo cuando este sea la causa. En cuanto al elemento subjetivo, se alude a los sujetos; es decir, a las partes en el proceso ya sean en su condición de actor o de demandado. En cuanto al objeto de la pretensión, es la finalidad por la cual se ejerce la acción, lo que se quiere alcanzar a través de esta. Finalmente, la causa constituye la razón o el fundamento jurídico de la pretensión.
} 
inimaginable, salvo que sea más bien el proceso contencioso el que acumule al civil, bajo una interpretación extensiva del denominado fuero de atracción existente en esta materia (lbídem, art 43).

Sin embargo, descartada la posibilidad de una acumulación procesal, queda la opción de la prejudicialidad y así, por ejemplo, un proceso civil por reconocimiento de mejoras introducidas en un inmueble podría ser suspendido cuando en la sede contenciosa se esté discutiendo la demolición de las mismas ante una disposición formal de contenido singular municipal; a juicio de quien suscribe el presente artículo, sería totalmente prudente -en consecuencia- suspender el proceso civil hasta tanto no se defina con certeza cuál será la situación de aquellas mejoras e, incluso, la influencia estará justificada por la necesidad de conocer a priori la legalidad o ilegalidad de las mismas.

\section{Una propuesta de análisis a la luz de dos presupuestos configuradores}

Finalmente, como último punto de este modesto ensayo, se hará énfasis en dos aspectos que, si bien ya fueron expuestos de una u otra manera en las páginas anteriores, conviene tenerlos presentes para no confundir a la prejudicialidad con otros institutos jurídicos tales como la cosa juzgada, la litispendencia, el fuero de atracción o la acumulación procesal.

\section{Presupuesto de modo: valorar existencia de una influencia necesaria}

En primer lugar, en la prejudicialidad el análisis debe radicar en determinar si otro proceso judicial, que no resulta acumulable, ejerce una influencia tal sobre el expediente judicial, de forma que sea absolutamente necesario suspender el curso de las actuaciones de este hasta tanto no se resuelva aquel expediente influyente.

Queda en consecuencia descartada aquellas hipótesis en la que más que influencia existe identidad (sea subjetiva, objetiva y causal) porque en estas, si el proceso se encuentra ya fenecido, lo que podría haber sería cosa juzgada (V.gr supuesto de demanda improponible (Ley 9342, art. 35.5.4)) y en caso de que se encuentre en trámite, sería litispendencia (Ibídem, art. 8.6) estos son escenarios en los cuales lo que se produce es la inadmisibilidad y consecuente archivo del proceso.

En tal sentido, se considera que la propuesta aquí expuesta es plenamente concordante con lo indicado por, López (2017, p.191), uno de los tres redactores del Código Procesal Civil, quien sostiene que:

A pesar de que el código, ajustándose a la doctrina procesal moderna reconoce la existencia de otros tipos de prejudicialidad (...) en todo caso será necesario que los Tribunales hagan un riguroso examen sobre la influencia que el otro proceso tenga en el civil, porque si esa influencia es inexistente o escasa, no hay justificación para desplegar esos efectos negativos para la justicia pronta.

En suma, será la concretización del concepto jurídico indeterminado de "influencia necesaria" el que brinde las luces requeridas para determinar si cabe o no la prejudicialidad; aspectos tales como seguridad jurídica, razonabilidad, proporcionalidad, evitar fallos contradictorios, necesidad previa de tener certeza sobre un punto en discusión, conexión lógica con el objeto de otro proceso, etc., son los que brindarán las pautas hermenéuticas idóneas para establecer tal necesidad. 


\section{Presupuesto de tiempo: valorarse de cara al dictado de sentencia}

Finalmente, por una cuestión de principio o si se quiere como un presupuesto innato al mismo instituto de la prejudicialidad, deberá siempre tenerse presente que esta solamente es valorable de cara a la decisión final del proceso civil, toda vez que razones de buena fe procesal, celeridad, impulso procesal y tutela judicial efectiva hacen absolutamente improcedente el decretar una suspensión en una fase inicial o intermedia del procedimiento.

La misma dinámica de un proceso jurisdiccional impone tal percepción y el mismo párrafo segundo del numeral 34.2 de la Ley $\mathrm{N}^{\circ} 9342$ avala tal razonamiento, pues se circunscribe el efecto a: "resolver sobre el objeto del litigio" y precisamente se resuelve el objeto cuando por el fondo se está de cara a la emisión de un fallo final en un proceso civil.

\section{Conclusiones}

I. La prejudicialidad es un instituto procesal que se presenta en aquel proceso judicial cuando de cara al dictado de la resolución final se tiene noticia, sea de oficio o a gestión de parte, de la existencia de otra causa judicial que, no siendo acumulable ni idéntica, ejerce una influencia tal que amerita por razones de prudencia y seguridad jurídica su consecuente suspensión.

2. La supresión, como regla de la prejudicialidad penal, en el nuevo proceso civil costarricense es una propuesta legislativa original y valiente, la cual se justifica en la misma experiencia jurisdiccional que denotó más que el uso su abuso; razones de tutela judicial avalan desde el plano constitucional su exclusión, quedando reservada, incluso desde el propio enfoque intraprocesal, la declaratoria inter-partes de alcance probatorio de la "falsedad documental" por el mismo Tribunal Civil.

3. El reconocimiento normativo de la prejudicialidad no penal en el ordenamiento procesal civil costarricense responde a una sentida necesidad. Lejos queda una dimensión servil del proceso civil hacia el penal, por el contrario, son las razones y no las materias las que en adelante justifican la procedencia o no del efecto suspensivo.

4. La procedencia de la prejudicialidad no penal debe estar supedita y antecedida de un análisis exhaustivo. La medida es de carácter residual y excepcional: residual puesto que primero deberá ser descartada la posibilidad de una acumulación y excepcional debido a que estará supedita a un tiempo y modo determinados, esto es, de cara a la resolución final del objeto del proceso y en ocasión de la absoluta influencia necesaria que habrá de irradiar la cuestión judicial pendiente de resolver sobre el proceso a suspender.

\section{Referencias bibliográficas}

\section{Normativa}

Código Civil de Costa Rica, Ley Nº 63.

Código de Comercio de Costa Rica, Ley N 3284.

Código Procesal Civil de Costa Rica, Ley No 7I30.

Código Procesal Civil de Costa Rica, Ley N ${ }^{\circ} 9342$.

Código Procesal Civil de Honduras.

Código Procesal Civil y Mercantil de El Salvador.

Ley de Enjuiciamiento Civil de España.

Código Procesal Contencioso Administrativo, Ley N ${ }^{\circ} 8508$.

Constitución Política de la República de Costa Rica.

Convención Americana de Derechos Humanos.

Ley General de la Administración Pública de Costa Rica, Ley Nº 6227.

Ley Orgánica del Poder Judicial de Costa Rica, Ley N 7333. 